\title{
A sociedade da informação no Brasil: um ensaio sobre os desafios do Estado
}

\author{
Rubens da Silva Ferreira \\ Mestrando em Planejamento do Desenvolvimento pelo Núcleo de \\ Altos Estudos Amazônicos-NAEA/UFPa, com área de concentração \\ em Políticas Públicas. Graduado em Biblioteconomia pela Universi- \\ dade Federal do Pará (2000). \\ E-mail: rubenspa@yahoo.com
}

\section{Resumo}

Aborda os desafios do Estado na consolidação de uma sociedade da informação no Brasil. Esses desafios são representados pelo analfabetismo, pela necessidade de capacitação dos recursos humanos da burocracia do Estado e pela dificuldade do cidadão comum ao acesso às tecnologias de informação. Entende que a sociedade da informação é algo ambivalente para o Estado brasileiro. Ela representa os desafios e as oportunidades para o desenvolvimento em uma ordem informacional, caracterizada pela velocidade das mudanças no contexto da sociedade contemporânea. Portanto, o Estado precisa elaborar e aplicar políticas públicas comprometidas com a real superação desses desafios, para a construção de uma sociedade da informação mais eqüitativa no Brasil.

\section{Palavras-chave}

Estado brasileiro; Sociedade da informação; Analfabetismo; Capacitação de recursos humanos; Tecnologia da informação; Políticas públicas.

\section{Information society in Brazil: an essay about the challenges of the State}

\begin{abstract}
This article treats of the challenges the State faces for consolidating an information society in Brazil. These challenges are illiteracy, the need of developing human resources and the difficulty of any citizen in accessing information technology. Information society is understood as something ambivalen for the Brazilian State. It represents challenges but at the same time opportunities for developing an informational order, characterized by very quick changes in a contemporary society. Therefore, the State has to elaborate and apply relevant public policies for overcoming these challenges in order to build up a more evenly accessible information society in Brazil.
\end{abstract}

\section{Keywords}

Brazilian state; Information society; Illiteracy; Human resources development; Information technology; Public policies.

\section{INTRODUÇÃO}

A sociedade da informação traz novas responsabilidades para todos os atores sociais nela inseridos. Essas responsabilidades denotam o dever desses atores para a provisão de um fluxo constante de informações que possibilitem a geração de novos conhecimentos e tomada de decisão nas várias instâncias da sociedade, inclusive no Estado. Vista sob esta ótica funcional, a informação pode ser entendida como um recurso redutor de incertezas (Wetherbe, 1987; Chiavenato, 1993), e, no que concerne ao desenvolvimento, ela pode viabilizar a elaboração, implementação e avaliação de políticas públicas com maior grau de eficácia e eficiência, a partir da análise da complexidade social em suas demandas e contradições. Há, portanto, no uso desse recurso, um continuum que o coloca em uma posição de destaque no pós-industrialismo, em que a informação gera conhecimento, e este, por sua vez, gera mais informação, dentro de uma estrutura circular virtuosa. Por conseguinte, tal estrutura, geradora desse fluxo perene de informação, tem levado estudiosos como Masuda (1982), Touraine (1999) e Castells (1999) a atribuir-lhe o status de recurso fundamental para o desenvolvimento da sociedade, tendo adquirido essa posição em função das transformações tecnológicas que a tornaram cada vez mais difusa no século XX.

Assim, para os diferentes atores da sociedade, a informação assume finalidades específicas. No âmbito do mercado, o acesso à informação visa à geração de vantagem competitiva sobre a concorrência, descoberta de novos nichos de consumidores; pesquisa e desenvolvimento de novos produtos e serviços, bem como o monitoramento do ambiente externo, a fim de identificar ameaças e/ou novas oportunidades de negócios para as empresas que o compõem. Por isso, cada vez mais, grandes corporações vêm realizando investimentos vultosos em sistemas de informação, objetivando interagir de forma mais rápida e dinâmica em áreas de produção, distribuição e comercialização de produtos estrategicamente espalhadas pelo planeta (Ferreira, 2000).

No campo do Estado, enquanto conjunto de instituições de poder legitimadas pela sociedade (Banco Mundial, 
1997), o acesso à informação tem por finalidade a manutenção da sua soberania. Nessa direção, o uso desse recurso é orientado no sentido de coordenar a complexidade social no que se refere à ordem, por intermédio de suas instituições legislativas, executivas e judiciárias. Em caráter específico, a informação no contexto do Estado está voltada para a análise da realidade social e subseqüente elaboração, aplicação e controle de políticas públicas* que promovam o bem-estar da coletividade.

Para a sociedade civil, o aceso à informação tem como propósito desenvolver o potencial criativo e intelectual dos indivíduos; entreter; dar sentido às ações dos homens no cotidiano; tornar públicas as proposições políticas e decisões que, tomadas na esfera do Estado, têm reflexos diretos sobre a qualidade de vida das populações. E, de um modo geral, permitir o exercício da cidadania, o que só é possível se os cidadãos tiverem o pleno conhecimento de seus direitos e deveres (Araújo, 1999; Rocha, 2000) enquanto membros da nação. Dessa maneira, formas organizativas da sociedade civil como ONGs, movimentos sociais, sindicatos e associações de bairro podem contribuir para que os cidadãos exerçam sua cidadania mediante provisão de informações relacionadas aos seus direitos políticos, civis e sociais conquistados historicamente.

Em um cenário em que as ciências sociais e suas subáreas analisam a crise do Estado como conseqüência dos ajustes estruturais ditados pelas reformas neoliberais para a implantação de uma lógica de mercado nas relações Estado/sociedade, os movimentos sociais e ONGs vêm proliferando anualmente no Brasil. Essa proliferação é interpretada, neste sentido, como uma atitude de reação e auto-iniciativa da sociedade civil, para se ocupar dos problemas sociais negligenciados pelo poder público e pelo mercado e, assim, "humanizar" o capitalismo (Pablo Falconer, 1999; Offe apud Rocha, op. cit.). A ascendência dessa reação social resulta, portanto, de uma descrença na capacidade de as instituições estatais e econômicas lidarem de forma efetiva com as questões de interesse da coletividade, principalmente em países com sérios entraves sociais, políticos e econômicos, para alcançar um nível satisfatório de desenvolvimento, como é o caso do Brasil.

\footnotetext{
* Entenda-se por políticas públicas a tomada de posição do Estado diante das demandas da sociedade, que se traduz, entre outras coisas, em legislações, programas e projetos de ação voltados à segurança, à educação, à geração de emprego e renda, à saúde, à regulação da economia, ao uso dos recursos naturais, à seguridade social e a tantos outros aspectos da vida econômica e social que puderem ser enumerados.
}

Partindo dessa perspectiva de mudança em que o paradigma pós-industrial imprime uma nova dinâmica à sociedade, ao Estado e aos agentes econômicos, países de diferentes realidades tecnológicas, políticas, sociais e culturais têm procurado se adaptar a este contexto. Reconhecida oficialmente como um recurso estratégico e propulsor do desenvolvimento pelo governo brasileiro por meio do Programa Sociedade da Informação, ${ }^{*}$ o qual teve suas diretrizes expressas no chamado Livro Verde (Sociedade, 2000)12, tal iniciativa visa a promover o uso das novas tecnologias de comunicação na esfera social, estatal e privada. Conforme evidencia o Livro Verde, o programa é um conjunto de ações governamentais ousadas e marcadas por muitos desafios. Porém, tais ações são necessárias em um mundo cada vez mais globalizado e competitivo, de forma que os países em desenvolvimento que se posicionarem de modo negligente a esta realidade ainda em conformação podem incorrer em atraso e isolamento tecnológico e econômico, provavelmente de difícil reversão, se contrastados com os países desenvolvidos que já puseram em curso seus projetos de construção de sociedades baseadas no uso intensivo de informação.

Neste contexto, o objetivo deste ensaio situa-se em um esforço de reflexão sobre os desafios que o Estado precisa enfrentar, a fim de que possa tornar-se efetiva a construção de uma sociedade da informação no Brasil, tal como tem almejado o governo federal em seu Programa Sociedade da Informação. Seguindo essa linha, serão discutidos três fatores considerados críticos para que o Estado possa produzir o resultado que espera. São eles: o analfabetismo, o acesso do cidadão comum às novas tecnologias de informação e a capacitação dos recursos humanos lotados na burocracia estatal.

\section{O ESTADO BRASILEIRO E SEUS DESAFIOS}

Antes de qualquer coisa, o Estado precisa encarar a informação como um recurso de gestão e desenvolvimento para o país. Nessa ótica, assim como se concebem políticas direcionadas para os setores de habitação, saúde, educação, segurança pública e geração

\footnotetext{
* O Programa Sociedade da Informação resultou de ampla discussão promovida pelo Conselho Nacional de Ciência e Tecnologia, realizada no ano de 1996, da qual participaram intelectuais, técnicos e especialistas de diferentes formações, organizados em temas desdobrados nos seguintes grupos de trabalho (GT): administração pública; ações empresariais; conteúdo e identidade cultural; cooperação internacional; divulgação à sociedade; educação; infraestrutura de redes e backbones; integração e regionalização; pesquisa e desenvolvimento; planejamento; processamento de alto desempenho e trabalho (Sociedade, 2000).
} 
de emprego e renda, cabe aos governos, em sua escala federal, estadual e municipal, desenvolver políticas de informação. Tais políticas, de natureza particular, referem-se às diretrizes e ações estratégicas capazes de orientar o uso eficaz desse recurso no campo da cultura, da política e da economia brasileira na sociedade da informação de acordo com os novos paradigmas, tais como a descentralização de processos, otimização de custos, participação social direta nas decisões políticas e gestão dos serviços públicos, bem como o livre acesso do cidadão à informação pública.

No atual momento em que se discute e revê o papel do Estado, torna-se oportuna a reflexão sobre as responsabilidades informacionais do poder público para com a sociedade. E, embora autores como Castells (apud Silveira, 2000) afirmem que o Estado é pequeno demais para enfrentar os desafios de uma sociedade da informação, cabe ressaltar que a capacidade adaptativa das instituições e seus reordenamentos estruturais manifestam-se em espaços temporais imprevisíveis e imensuráveis, principalmente se considerarmos a conjuntura ainda recente dos acontecimentos que se desencadearam a partir do século $\mathrm{XX}$, aos quais os Estados nacionais vêm se ajustando em maior ou menor ritmo e escala de tempo. Assim, não convém acreditar em um determinismo negativo que subjuga o poder de reação do Estado em seu conjunto de instituições, em face das mudanças paradigmáticas que bem representam a sociedade da informação.

No Brasil, o governo federal, por meio do Conselho Nacional de Ciência e Tecnologia, tem mostrado sua capacidade de reação ao paradigma tecnoinformacional. De acordo com o Programa Sociedade da Informação, idealizado em 1996, pretende-se, por intermédio de serviços de computação, comunicação e informação, estruturar as bases para uma ação de alcance nacional, voltada para a sociedade civil, para a pesquisa, para a educação e para o setor econômico, com o propósito de construir uma sociedade da informação brasileira (Miranda, 2000). O fator-chave desse programa está concentrado em uma complexa plataforma tecnológica, pela qual se espera elevar o número de cidadãos conectados à Internet, possibilitando, desse modo, o amplo acesso à informação, inclusive àquela produzida pelo próprio Estado e disponibilizada em web sites governamentais (Pimenta, 1998).

Em que pesem os objetivos do programa, a crítica que se faz pousa em grande paradoxo entre o que o governo federal almeja alcançar em termos de objetivos e metas e o que a realidade social brasileira é de fato*. Tal antinomia pode, neste sentido, ameaçar as expectativas do programa quanto aos resultados esperados pelo poder público federal. De maneira mais precisa, enquanto o Estado pretende acabar com o "analfabetismo digital" condição necessária para a inserção do cidadão na sociedade virtual em rede -, muitos brasileiros ainda permanecem à parte da produção e da compreensão da palavra escrita, a qual soa mais como um privilégio de poucos, do que como um direito de todo o cidadão. Portanto, o analfabetismo é o maior desafio a ser enfrentado pelo Estado para a consolidação de uma sociedade da informação no Brasil, uma vez que os estoques de informação disponíveis na Internet encontram-se, em sua maioria, sob a forma de texto escrito, inacessíveis para cerca de 20 milhões de brasileiros que não sabem ler e escrever (Baggio, 2000). Este desafio evidencia, portanto, que a educação ainda é a melhor via para que um país alavanque seu processo de desenvolvimento, com maiores possibilidades de inclusão e igualdade de oportunidades para o cidadão.

O projeto Alfabetização Solidária, implementado pelo programa Comunidade Solidária, é uma iniciativa de capital importância no combate ao analfabetismo no Brasil. Contudo, nas escolas públicas, pouco inovou-se nos métodos de ensino diante das possibilidades ainda inexploradas de aprendizado oferecidas pelas novas tecnologias de comunicação e informação, as quais permitem a manipulação de diferentes mídias (texto, imagem e som) em uma relação mais interativa entre sujeito cognoscente e conhecimento. De modo geral, podem contribuir para essa "estagnação metodológica", tanto a resistência (Assmann, 2000) quanto a falta de preparo dos professores para lidar com a metamorfose do processo ensino/aprendizado na sociedade da informação. Demanda-se, neste caso, a preparação desses docentes para atuar em um ambiente escolar no qual o papel do educador aumenta em grau de importância, no sentido de que o processo ensino/aprendizado precisa ser administrado de maneira mais dinâmica e criativa.

\footnotetext{
* Entenda-se, no sentido de uma realidade social brasileira enquanto tal, o emaranhado de problemas sociais historicamente não resolvidos, como é o caso da reforma agrária, emperrada na agenda política do Estado por uma tradição de três séculos de escravismo colonial (Silva, 1996), responsável pela acentuada concentração fundiária no Brasil até os dias de hoje. SILVA, Francisco Carlos T. da. A modernização autoritária: do golpe militar à redemocratização 1964/1984. In: LINHARES, Maria Y. (Org.). História geral do Brasil. Rio de Janeiro: Campus, 1996. p. 301-334
} 
Do ponto de vista tecnológico, a dificuldade para a construção de uma sociedade da informação brasileira não é menos tênue que o problema do analfabetismo. Para muitos trabalhadores assalariados, o computador e a Internet ainda são categorizados como bens de luxo, pois o preço médio desse equipamento corresponde a cerca de um terço da renda média anual per capita do Brasil (Sociedade, 2000, p. 37). E, apesar de algumas escolas do ensino público contarem com esses recursos para seus alunos, os cidadãos não matriculados nesses estabelecimentos de ensino permanecem excluídos do usufruto das novas tecnologias de comunicação e informação.

Dessa maneira, se o governo federal pretende ampliar o número de brasileiros conectados à Internet, terá também de realizar a democratização da informática, tal como vem fazendo o Comitê para Democratização da Informática (CDI), uma ONG idealizada por Rodrigo Baggio, em 1993, que tem como objetivo permitir o acesso de cegos, doentes mentais, presos, minorias étnicas e comunidades carentes em geral ao uso de recursos computacionais e telemáticos essenciais no advento da sociedade da informação (Baggio, op. cit.). Embora o CDI esteja presente em 23 cidades brasileiras e quatro países (Japão, México, Colômbia e Uruguai), tendo capacitado até 1995 cerca de 48 mil brasileiros (idem), o Estado continua cada vez mais necessário na sociedade, no que se refere à elaboração e execução de políticas sociais de inclusão de longo alcance, principalmente se o poder público somar esforços com a iniciativa de outros atores sociais - como o CDI -, para intervir em questões que ele não consegue resolver sozinho em seu momento de crise e reajuste institucional.

A democratização da informática no contexto de uma ação estatal precisa, a nosso ver, transpor os muros das escolas e universidades e atingir o maior número possível de cidadãos não-alunos. Pode-se pensar, neste caso, na construção de unidades de informação pública, distribuídas em bairros populares, estruturadas com computadores ligados à Internet e administradas por membros da comunidade habilitados para cadastrar e orientar o cidadão na busca da informação desejada, seja em web sites governamentais, científicos, de arte, turismo ou lazer. Ações dessa natureza têm sido executadas, por exemplo, em Curitiba, como resultado da parceria entre a prefeitura e o CDI (Sociedade, 2000, p. 38) na disponibilização de serviços gratuitos de acesso à Internet em pontos estratégicos da cidade.
Contudo, é um erro pensar que a democratização da informática irá levar à completa democratização da informação. A primeira forma representa apenas uma contribuição para a segunda, a qual constitui um processo mais amplo e que envolve não apenas os conteúdos informacionais disponíveis na Internet, mas toda a informação produzida na sociedade, registrada nos mais diferentes suportes e de interesse público. A democratização da informática é, portanto, um meio para um fim maior, dado que os recursos computacionais e telemáticos são apenas ferramentas que podem potencializar a disseminação da informação, ao eliminar velhas barreiras espaciais e temporais que limitavam o fluxo informacional entre sociedades até a segunda metade do século XX.

No que se refere à Internet, cabe lembrar que ela apresenta muitas questões a serem consideradas quanto à democratização da informação. A popularização dessa rede mundial, por exemplo, trouxe consigo uma quantidade expressiva de informação, muitas vezes de qualidade duvidosa, servindo mais para desinformar do que informar o cidadão. Basta lembrar, nessa perspectiva, a propagação de sites neonazistas, que difundem livremente informações de conteúdo racista e preconceituoso, divulgando uma visão artificial e distorcida sobre o que foi o Holocausto promovido por Hitler a partir de 1933, ou ainda, sites estruturados com conteúdos de pedofilia, acessados mundialmente por uma rede de indivíduos investigados pela polícia internacional. Cabe ao Estado, portanto, discutir, junto à sociedade civil e atores econômicos, ações capazes de coibir a veiculação de informações dessa natureza. E, da mesma forma, pensar e estimular a disponibilização de conteúdos informacionais na Internet que promovam a formação intelectual e cultural do indivíduo, uma vez que a rede mundial de computadores - enquanto espaço até o momento livre de qualquer regulamentação consistente - tem publicizado informações sem considerar os princípios humanos e éticos sobre os quais a democratização da informação deve fundamentar-se.

A reflexão sobre as possibilidades de atuação do poder público na sociedade pós-industrial - no que se refere à democratização da informação e da informática - traz à tona a questão da capacitação dos recursos humanos que irão atuar nesse novo modelo de sociedade. Capacitação que precisa ir além do simples "adestramento tecnológico", pois no trabalho informacional a atenção deve concentrar-se na produção e disseminação de conteúdos informacionais qualitativos. Assim, o quadro funcional tutelado pelo 
poder público precisa ser preparado para trabalhar sob a perspectiva do processo de que se constituem as práticas de coleta, processamento e disseminação da informação, a fim de prestar serviços informacionais mais eficientes à sociedade.

$\mathrm{Um}$ aspecto relevante que precisa ser considerado na capacitação de pessoal corresponde ao emprego de abordagens comportamentais positivas. Tais abordagens precisam estimular o desenvolvimento de uma cultura organizacional comprometida com a provisão de um fluxo constante de informação, livre de erros, sempre atualizado e sem redundância (Ferreira, op. cit.). A reforma administrativa é o momento oportuno para que o governo federal inclua, em seu Programa Nacional de Capacitação do Servidor Público, cursos voltados para o aprendizado e o trabalho informacional nas organizações estatais, envolvendo não apenas o pessoal situado no nível alto e intermediário da burocracia, mas também os servidores inseridos no nível operacional que lidam diretamente com o cidadão, haja vista que a reforma administrativa, na agenda do Estado, tem entre seus princípios a ênfase na prestação de serviços públicos de qualidade para o cidadão (Pimenta, op. cit.), e qualidade é algo diretamente ligado à informação (Moura, 1995), no sentido de que ela gera conhecimentos sobre o grau de satisfação dos consumidores de serviços públicos e privados.

Escolas públicas de governo, como a Escola Nacional de Administração Pública (Enap), têm importante papel no atendimento das demandas dos servidores públicos por capacitação, cabendo aos governos federal, estadual e municipal buscar parcerias com instituições tradicionalmente dedicadas à formação de profissionais na área de informação, para a oferta de cursos que contribuam para o melhor desempenho do trabalho informacional nas repartições públicas. Em síntese, a capacitação técnica do quadro humano em atuação no poder público é um fator crítico para a construção de uma sociedade da informação no Brasil, como tem objetivado o governo federal em seu programa, pois a qualidade das informações publicizadas para a sociedade dependerá, essencialmente, do modo como ela foi tratada em seu trâmite no corpo burocrático do Estado.

\section{CONSIDERAÇÕES FINAIS}

Em resumo, para o poder público, a sociedade da informação é algo ambivalente, como abordamos até aqui. Ela representa para o Estado os desafios e as oportunidades de um novo arranjo político, social, econômico e tecnológico. Desafio que o leva a rever sua legislação civil, comercial e penal, para dar conta dos novos comportamentos sociais que emergem de uma ordem agora informacional. A pensar formas de educação inovadoras para o ensino público, com o advento dos computadores pessoais e da telemática. A buscar novos mecanismos de fazer política, com a participação popular e o livre acesso do cidadão à informação pública. A capacitar os recursos humanos do aparelho estatal para o trabalho informacional. A produzir conteúdos nacionais qualitativos, de interesse público e com valor agregado, capazes de promover o desenvolvimento político e cultural da coletividade.

Entretanto, a sociedade da informação desponta como oportunidade no que se refere ao uso dos novos métodos e técnicas para o processamento da informação, sem os quais esse recurso não teria adquirido o caráter de fenômeno na modernidade. É por meio desses recursos tecnológicos que o poder público pode interagir mais com a sociedade, conhecendo novas demandas e proposições políticas de grupos sociais antes limitados em seus canais de comunicação com o Estado. Oportunidade de investir em ciência e tecnologia, a fim de que o conhecimento produzido seja revertido na qualidade de vida da população. De ampliar o acesso do cidadão à educação, com a participação de sindicatos, empresas privadas, ONGs e outras formas organizativas da sociedade comprometidas com o desenvolvimento da cidadania. Cidadania cuja prerrogativa do seu exercício passa, necessariamente, pelo direito de acesso à informação, como condição elementar para a conquista de novos direitos políticos, civis e sociais, em uma sociedade cada vez mais caracterizada pela velocidade das mudanças que nela ocorrem, exigindo, assim, grande capacidade adaptativa das instituições e grupos sociais que a constituem.

A consolidação de uma sociedade da informação mais eqüitativa depende, portanto, da superação dos desafios elementares arrolados neste ensaio, no sentido de que as oportunidades que se abrem possam ser mais bem aproveitadas pelo Estado e pela sociedade civil. Ao colocar em prática um projeto de valor estratégico para o desenvolvimento brasileiro, antes que tenham sido resolvidas antigas questões da agenda política, o Estado 
pode, na mais simples das hipóteses, reproduzir uma estrutura social cada vez mais excludente e desigual, muito distante da concepção masudiana de uma sociedade da informação democrática e igualitária. Daí a necessidade de uma tomada de posição do Estado comprometida com a eliminação desses entraves, por meio de políticas públicas voltadas para a real inclusão do cidadão, em um contexto em que a informação é preconizada como a nova força motriz do desenvolvimento.

Artigo aceito para publicação em 19-11-2002

\section{REFERENCIAS}

ARAÚJO, Eliany Alvarenga. Informação, sociedade e cidadania: gestão da informação no contexto das Organizações Não-Governamentais brasileiras. Ciência da Informação, Brasília, v. 29, n. 2, p. 155-167, maio/ago. 1999.

ASSMANN, Hugo. A metamorfose do aprender na sociedade da informação. Ciência da Informação, Brasília, v. 29, n. 2, p. 7-15, maio/ ago. 2000.

BAGGIO, Rodrigo. A sociedade da informação e a infoexclusão. Ciência da Informação, Brasília, v. 29, n. 2, p. 16-21, maio/ago. 2000.

BANCO MUNDIAL. Relatório sobre o desenvolvimento mundial. [S.1.],

1997. p. 19-63.

CASTELLS, Manuel. A sociedade em rede. São Paulo : Paz e Terra, 1999.

CHIAVENATO, Idalberto. Introdução à teoria geral da administração. 4. ed. São Paulo : Makron, 1993.
FERREIRA, Rubens da Silva. Gerenciamento da informação no contexto empresarial: uma abordagem sob o prisma da ecologia da informação. 2000. 75 f. Monografia (Curso de Biblioteconomia - UFPa) - UFBA, Belém, 2000.

MASUDA, Yoneji. A sociedade da informação como sociedade pós-industrial. Rio de Janeiro : Editora Rio, 1982.

MIRANDA, Antonio. Sociedade da informação: globalização, identidade cultural e conteúdos. Ciência da Informação, Brasília, v. 29, n. 2, p. 78-88, maio/ago. 2000.

MOURA, Luciano Raizer. Informação: a essência da qualidade. Ciência da Informação, Brasília, v. 25, n. 1, 1995. Disponível em: http://www.ibict.br/cionline/250195/index.htm. Acesso em: 20 jun.1999.

PABLO FALCONER, Adreas. A promessa do terceiro setor: um estudo sobre a construção do papel das organizações sem fins lucrativos e do seu campo de gestão. São Paulo : Centro de Estudos em Administração do Terceiro Setor, USP, 1999. $23 \mathrm{f}$.

PIMENTA, Carlos César. A reforma gerencial do Estado brasileiro no contexto das grandes tendências mundiais. In: REUNIÃO DE ESPECIALISTAS DO PROGRAMA DAS NACOÕES UNIDAS EM ADMINISTRAĈ̣̃O PÚBLICA E FINANÇAS, 14., 1998, Nova Iorque, Anais... Nova Iorque : [s. n.], 1998. p. 2-25.

ROCHA, Marisa Perrone Campos. A questão da cidadania na sociedade da informação. Ciência da Informação, Brasília, v. 29, n. 1, p. 40-45, jan./abr. 2000.

SILVEIRA, Henrique Flávio Rodrigues da. Um estudo do poder na sociedade da informação. Ciência da Informação, Brasília, v. 29, n. 3, p. 79-90, set./dez. 2000.

SOCIEDADE da Informação no Brasil: livro verde. Brasília: Ministério da Ciência e Tecnologia, 2000. Disponível em: http:// www.socinfo.org.br/livro_verde/dowload.htm. Acesso em: 16 abr. 2002.

TOURAINE, Alan. A volta do capitalismo. São Paulo : EDUSC, 1999.

WETHERBE, J. C. Análise de sistemas para sistemas de informação por computadores. São Paulo : Campus, 1987. 